\title{
Endothelial Cell Heterogeneity
}

\author{
William C. Aird \\ Department of Medicine, Center for Vascular Biology Research, Beth Israel Deaconess Medical Center, \\ Harvard Medical School, Boston, Massachusetts 02215 \\ Correspondence: waird@bidmc.harvard.edu
}

The endothelial lining of blood vessels shows remarkable heterogeneity in structure and function, in time and space, and in health and disease. An understanding of the molecular basis for phenotypic heterogeneity may provide important insights into vascular bed-specific therapies. First, we review the scope of endothelial heterogeneity and discuss its proximate and evolutionary mechanisms. Second, we apply these principles, together with their therapeutic implications, to a representative vascular bed in disease, namely, tumor endothelium.

$T^{\text {he }}$ he endothelium forms the inner cellular lining of blood vessels. It is now well established that endothelial cells are highly metabolically active, and play a critical role in many physiological processes, including the control of vasomotor tone, the trafficking of blood cells between blood and underlying tissue, the maintenance of blood fluidity, permeability, angiogenesis, and both innate and adaptive immunity. It is also recognized that the endothelium is involved in most if not all disease states, either as a primary determinant of pathophysiology or as a victim of collateral damage. However, there exists a wide bench-to-bedside gap in endothelial biomedicine. Although searches of PubMed using the key words endothelial cells or endothelium reveal $>100,000$ publications, clinicians have little awareness of the endothelium in health and disease (reviewed in Hwa et al. 2005).

The bench-to-bedside gap in endothelial biomedicine may be explained on several levels. First, there is a tendency for clinicians to focus on the large conduit vessels of the vascular tree. Indeed the very terms vascular medicine, vascular surgery, and vascular research conjure up images of atherosclerotic lesions in coronary, carotid, and femoral arteries, thrombosis in the deep veins of the legs, and emboli in the pulmonary arteries. Second, the endothelium flies below the clinical "radar screen." The endothelium is not amenable to traditional physical diagnostic maneuvers of inspection, palpation, percussion, and auscultation. Like blood cells, the endothelium is pervasive, reaching to all recesses of the human body. However, in contrast to circulating cells, endothelial cells are tethered to the blood vessel wall and are thus poorly accessible. Further, the endothelium has enormous untapped potential as a therapeutic target. A final consideration in explaining the bench-to-bedside gap in the field relates to the heterogeneous properties of the endothelium. Far from being a giant monopoly or collective of identical cells, the endothelium comprises an enormous consortium of

Editors: Michael Klagsbrun and Patricia D'Amore

Additional Perspectives on Angiogenesis available at www.perspectivesinmedicine.org

Copyright (C) 2012 Cold Spring Harbor Laboratory Press; all rights reserved; doi: 10.1101/cshperspect.a006429

Cite this article as Cold Spring Harb Perspect Med 2012;2:a006429 
W.C. Aird

different enterprises, each with its own identity. Indeed, endothelial cell phenotypes vary in space and time, in structure and function, and in health and disease (reviewed in Aird 2007a,b).

The goal of this article is to review phenotypic heterogeneity as a core property of the endothelium. The first part of the article will underscore the breadth of heterogeneity across the vascular tree. The second part will address proximate and evolutionary mechanisms of endothelial cell heterogeneity. In the last section, we will show how these principles can be applied to an understanding of tumor blood vessels. A similar approach may be used to dissect any number of vascular beds in health and disease, and thus help bridge the benchto-bedside gap in the field of endothelial biomedicine.

\section{ENDOTHELIAL CELL PHENOTYPES}

Endothelial cell heterogeneity has been described at the level of cell morphology, function, gene expression, and antigen composition (reviewed in Aird 2007a,b). Endothelial cell phenotypes vary between different organs, between different segments of the vascular loop within the same organ, and between neighboring endothelial cells of the same organ and blood vessel type. For example, at a structural level, endothelial cells that line straight segments of arteries, but not veins, are oriented along the longitudinal axis of blood flow (reviewed in Aird 2007a). Previous studies have shown that flow-dependent alignment of endothelial cells represents reversible endothelial structural remodeling in response to hemodynamic shear stress (Flaherty et al. 1972). The transfer of material across the endothelium, a process termed transcytosis, is mediated by caveolae and vesiculo-vacuolar organelles (VVOs). Caveolae are 70-nm membranebound, flask-shaped vesicles that open to the luminal or abluminal side of the cell. The density of caveolae in capillary endothelium (up to 10,000 per cell) greatly exceeds that in the arteries, arterioles, veins, or venules (reviewed in Bendayan 2002). An exception is the blood-brain barrier, where the number of caveolae is greatly reduced (Simionescu et al. 2002). VVOs comprise focal collections of membrane-bound vesicles and vacuoles (Dvorak and Feng 2001). They are most prominent in venular endothelium. In contrast, clathrincoated pits, which are involved in endocytosis, are particularly prominent in liver sinusoidal endothelium.

The endothelium of arteries and veins forms a continuous uninterrupted layer of cells, held together by tight junctions. The endothelium of capillaries may be continuous, fenestrated, or discontinuous, according to the needs of the underlying tissue. Fenestrated endothelium is characteristic of organs involved in filtration or secretion, including exocrine and endocrine glands, gastric and intestinal mucosa, choroid plexus, glomeruli, and a subpopulation of renal tubules. Discontinuous endothelium is similar to fenestrated endothelium, with the exception that the fenestrations are larger in diameter (they may manifest as gaps in the cell) and they lack a diaphragm (Wisse 1970). Moreover, the underlying basement membrane is poorly formed. Discontinuous endothelium is found in certain sinusoidal vascular beds, including the liver.

In addition to differences in structure, endothelial cells show remarkable heterogeneity in function. For example, basal and inducible permeability is differentially regulated across the vascular tree (reviewed in Aird 2007a). Constitutive flow of material between blood and underlying tissue takes place primarily at the level of capillaries. Transport of fluids and small solutes occurs in between cells (the so-called paracellular route), whereas macromolecules are transferred through the cell (the transcellular route) via caveolae VVOs and transendothelial channels. Basal permeability is lower in nonfenestrated vascular beds that are enriched in tight junctions and possess fewer caveolae (e.g., the blood-brain barrier). As evidence for the role of tight junctions in mediating barrier functions, mice that are null for the tight junction molecule, claudin-5, have a selective barrier defect in the brain (Nitta et al. 2003). Inducible permeability refers to changes in barrier 
function that occur in acute or chronic inflammation. These changes take place primarily in postcapillary venules. The extent to which regulated leakiness is mediated by paracellular or transcellular pathways is debated. The predilection for postcapillary venules as a site for inducible permeability may be explained by the relative abundance of VVOs, the relatively low number of tight junctions, and/or high expression levels of agonist-responsive receptors (reviewed in Aird 2007a). Severe inflammation may result in increased permeability in sites other than postcapillary venules, including large veins, arterioles, and capillaries.

The endothelium plays a key role in regulating the trafficking of leukocytes between blood and underlying tissue (hence, the metaphor of the endothelium as gatekeeper). Leukocyte trafficking involves a multistep cascade that begins with rolling, followed by firm adhesion and transmigration (reviewed in Butcher 1991, Springer 1994, and Aurrand-Lions et al. 2002). As with transfer of fluids and solutes, transmigration may occur between endothelial cells (the paracellular pathway) or through endothelial cells (the transcellular pathway). Each step in the cascade is mediated by the up-regulation of cell adhesion molecules on the surface of the endothelium as well as the expression of chemokines. Binding of endothelial E-selectin and P-selectin to leukocyte carbohydrate-based ligands promotes rolling of leukocytes to the endothelium, whereas binding of endothelial cell adhesion molecules, including vascular cell adhesion molecule (VCAM)-1 and intercellular adhesion molecule (ICAM)-1 to leukocyte integrins mediates firm adhesion. The mechanisms of transmigration are poorly understood, but involve CD31 and junctional adhesion molecule-1. Similar to inducible permeability, transfer of white blood cells occurs primarily in postcapillary venules. One mechanism underlying this site specificity is the preferential expression of E-selectin, P-selectin, VCAM-1, and ICAM-1 in the endothelium of postcapillary venules. Under certain conditions, leukocyte trafficking may occur in other segments of the vascular tree, including large veins, arterioles, and capillaries. For example, previous studies suggest that leukocyte sequestration and transmigration in the pulmonary circulation occurs primarily in alveolar capillaries by a rolling- and E-/Pselectin-independent mechanism that involves trapping of poorly deformed activated leukocytes on activated endothelium (Nishio et al. 1998; Basit et al. 2006). Similarly, in liver inflammation, the majority of leukocyte adhesion occurs in the sinusoidal endothelium (Wong et al. 1997). Another form of leukocyte trafficking is the transmigration of lymphocytes across the specialized postcapillary venules, termed high endothelial venules (HEVs), which are located in secondary lymphoid organs (reviewed in Miyasaka and Tanaka 2004). Trafficking at these sites occurs constitutively, and is mediated by interactions between lymphocyte L-selectin and its ligand on HEV endothelial cells (peripheral node addressin). In summary, the "universal cascade" for leukocyte trafficking is, in fact, mediated by spatially and temporally diverse mechanisms.

The endothelium is integrally involved in mediating hemostasis. The liver synthesizes and releases into the circulation a relatively constant amount of precursor serine proteases (zymogens) of the clotting cascade, the structural molecule fibrinogen and certain natural anticoagulant molecules including antithrombin III (ATIII), protein C, and protein S. Endothelial cells, in contrast, are mini factories for the regulatable production of many procoagulants and anticoagulants. Each of these mediators is differentially expressed across the vascular tree (reviewed in Rosenberg and Aird 1999 and Aird 2001). For example, the endothelial protein $C$ receptor is primarily expressed in large vessels (Laszik et al. 1997), tissue factor pathway inhibitor in microvessels (Osterud et al. 1995), and tissue-type plasminogen activator in pulmonary and cerebral arteries (Levin et al. 2000). In response to systemic inflammation, the expression of these various procoagulants and anticoagulants changes in ways that differ between vascular beds. Thus, the picture that emerges is one of heterogeneity layered on heterogeneity, such that endothelial cells from different sites of the vascular tree use 
W.C. Aird

site-specific "formulas" of hemostatic proteins to maintain blood in its fluid state and to promote limited clot formation when there is a breech in the integrity of the vascular wall. As a result, whenever there is a reduction or increase in the production of hemostatic proteins in the liver (e.g., in congenital and acquired hemophilias or deficiency states of ATIII, protein $\mathrm{C}$ or protein $\mathrm{S}$ ), the resulting systemic imbalance is incorporated into the unique local hemostatic balance of individual vascular beds, resulting in site-specific responses. This "channeling" by the endothelium may explain why in humans and animal models, systemic imbalance of clotting factors results in a local thrombotic phenotype (reviewed in Rosenberg and Aird 1999).

Recent studies have emphasized the existence of structural and functional heterogeneity of endothelial cells during angiogenesis. For example, endothelial sprouts comprise leading-edge tip cells followed by morphologically and functionally distinct stalk cells. The tip cells are enriched in filopodia and in response to guidance cures, they promote the extension of new sprouts and fusion with adjacent sprouting capillaries to form new vascular connections (reviewed in Franco et al. 2009). This process involves the coordinated activity of Notch and Wnt signaling.

Spatial and temporal differences in the structure and function of endothelial cells ultimately reflect differences in messenger RNA (mRNA) and protein expression. Endothelial cell genes may be classified according to whether they are constitutively or inducibly expressed, whether they are specific or not to endothelial cells, and whether they are expressed throughout the endothelium or in subsets of endothelial cells (reviewed in Minami and Aird 2005). There are remarkably few endothelial-specific genes that are constitutively expressed throughout the vascular tree. VE-cadherin and Robo4 are two such genes. There are many more examples of endothelial-restricted genes whose constitutive and/or inducible expression is limited to subsets of endothelial cells. As discussed above, the hemostatic genes are differentially expressed in a constitutive manner across the vascular tree. As another example, there are several endothelial markers that are expressed specifically on the venous versus arterial side of the circulation (reviewed in Aitsebaomo et al. 2008). Endothelial cells from different arteries, and even from different sites of the same artery, express overlapping but distinct molecular profiles (Passerini et al. 2004; Zhang et al. 2008). An example of an inducible, endothelial-restricted gene is E-selectin, which is expressed in activated, but not "resting" endothelium. In activated endothelium, E-selectin expression is largely confined to postcapillary venules (Petzelbauer et al. 1993).

In vivo proteomic approaches have revealed a striking array of vascular bed-specific phenotypes (reviewed in Ruoslahti and Rajotte 2000 and Simonson and Schnitzer 2007). For example, antibody and subfractionation strategies have been used to generate monoclonal antibodies that specifically target the caveolae in one vascular bed or another (McIntosh et al. 2002). Others have used phage display peptide libraries to select for peptides that home to specific vascular beds in vivo (Pasqualini and Ruoslahti 1996; Arap et al. 2002b). These latter studies have uncovered a vascular address system that allows for site-specific targeting of biologically active compounds, for example, to the endothelial lining of tumor blood vessels (Arap et al. 1998, 2002a).

\section{MECHANISMS OF ENDOTHELIAL CELL HETEROGENEITY}

Endothelial cell heterogeneity is mediated by one of two proximate mechanisms (Fig. 1) (Aird 2006). First, some site- and timedependent differences in endothelial properties are governed by differences in the extracellular milieu. Because blood vessels are distributed throughout the body, their endothelial lining is exposed to an enormous variety of tissue microenvironments. Insofar as endothelial cells are capable of sensing and responding to their environment, the wide range of signal inputs from one organ to the next is sufficient to generate phenotypic heterogeneity across the vascular tree. When endothelial cells are removed 
Endothelial Heterogeneity
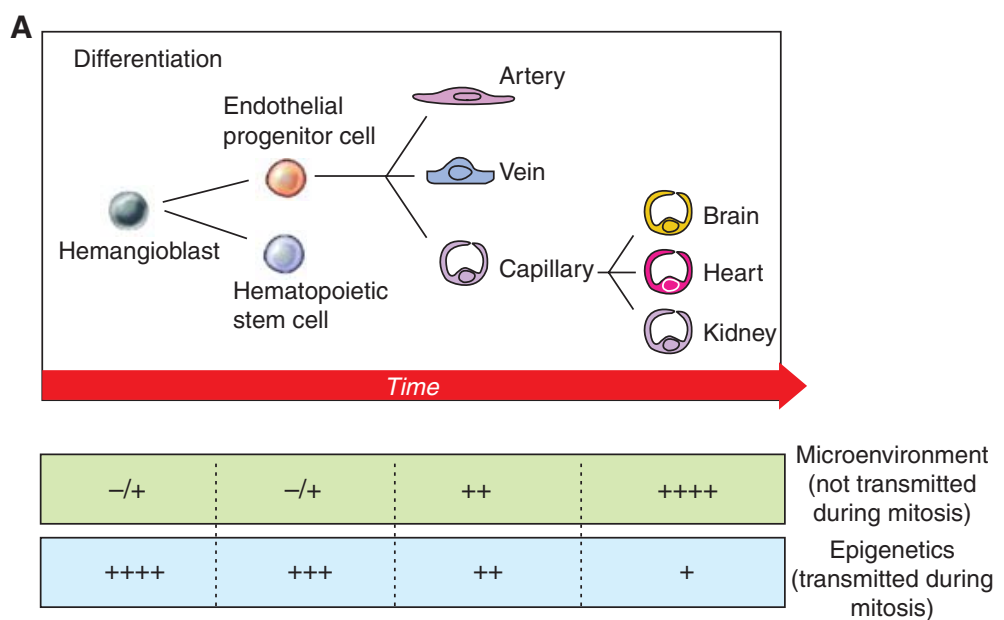

B Microenvironment

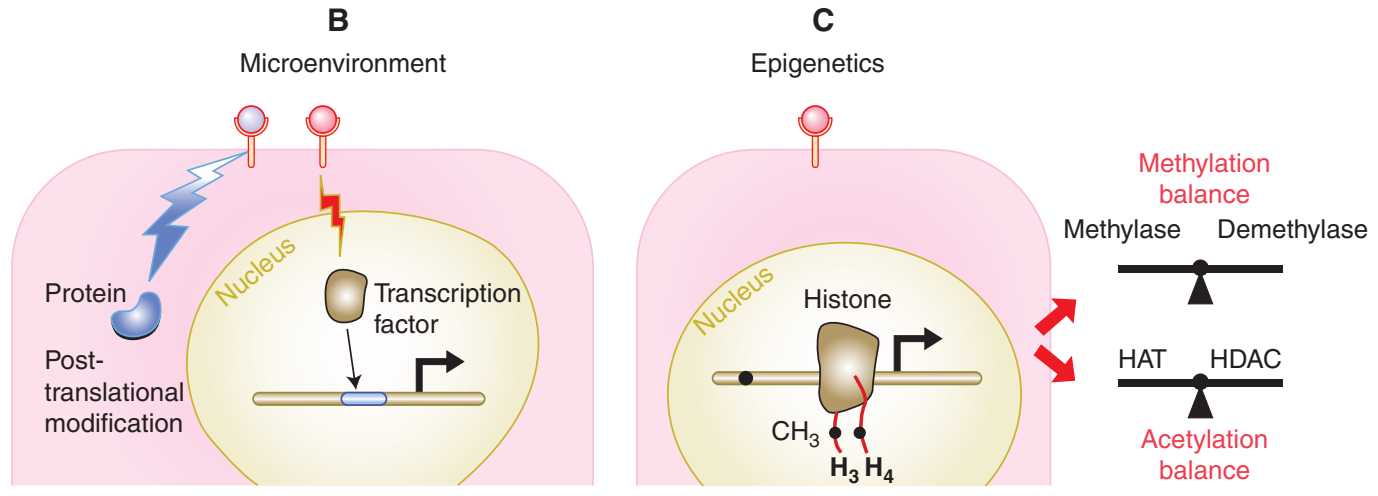

C

Epigenetics mitosis)

Figure 1. Mechanisms of endothelial cell heterogeneity. (A) Hemangioblasts give rise to endothelial progenitor cells (angioblasts), which in turn differentiate into endothelial cells of arteries, veins, and capillaries. Cell phenotypes are represented by color shades. Shown is the hypothetical relative role of microenvironment and epigenetics in mediating cell type-specific phenotypes. (B) The role of the microenvironment in mediating nonheritable changes in endothelial cell phenotype is represented by receptor-mediated posttranslational modification of protein (e.g., phosphorylation of a signal intermediate) and transcription factor-dependent induction of gene expression. Removal of the extracellular signal will result in eventual loss of translational/ transcriptional effects, and residual effects will be "diluted out" with cell division. $(C)$ The role of epigenetics in mediating heritable changes in endothelial cell phenotype is represented by DNA methylation $(\bullet)$, histone methylation $\left(\mathrm{CH}_{3}, \bullet\right)$, and histone acetylation (red lines), which in turn negatively or positively influences gene expression. Methylation is regulated by a balance between methylases and demethylases, whereas acetylation of histones is mediated by a balance between histone acetyltransferases (HAT) and histone deacetylases (HDAC). Although epigenetic modifications are triggered by extracellular signals and are dynamically regulated, they may persist on removal of the signals, and are transmitted during mitosis. (Figure is from Aird 2007a; reprinted, with permission, from the author.)

from their native tissue and grown in tissue culture, they become uncoupled from critical extracellular cues and undergo phenotypic drift. For this reason, studies of cultured endothelial cells are fraught with limitations. Second, certain site-specific properties are epigenetically "fixed" and impervious to changes in the extracellular environment. Such properties are mitotically stable, and are thus retained under in vitro culture conditions. The relative roles of epigenetic and nonepigenetic forces in mediating phenotypic heterogeneity are not fully 
W.C. Aird

understood. A previous DNA microarray study of multiple human endothelial cell types grown in culture revealed site-specific signatures even in multiple passaged cells, providing genomewide evidence for the importance of epigenetics in mediating differential gene expression (Chi et al. 2003). A study of endothelial cells from human tonsils revealed that approximately $50 \%$ of the vascular bed-specific genes were "washed out" when cultured in vitro, implicating a role for both the tissue environment and epigenetics in mediating differential gene expression (Lacorre et al. 2004). This conclusion was supported by a DNA microarray study in which the transcriptome of endothelial cells harvested from the porcine coronary artery was compared with those from the iliac artery. The data revealed that most, but not all, differences observed in vivo were lost in multiply passaged cells (Burridge and Friedman 2010).

In addition to proximate mechanisms, every biological trait requires an evolutionary explanation. Proximate explanations (how?) use traditional approaches of cell biology and molecular biology to determine the anatomy, physiology, and ontogeny (developmental history) of a trait at the level of a single organism. In contrast, evolutionary explanations (why?) draw on the fossil record and comparative morphology and DNA sequences to uncover the phylogeny (evolutionary history) of a trait as well as the fitness advantage that the trait provides at the level of a population or species (Tinbergen 1963). Comparative studies have revealed that the endothelium is present in all vertebrate species, but absent in invertebrates. Thus, the endothelium evolved in a common ancestor of the vertebrates following the divergence of the urochordates and cephalochordates some 500 million years ago over a period of only 50 million years. This same short period witnessed the evolution of a closed circulation, the clotting cascade, and acquired immunity.

An interesting question is whether endothelial cell heterogeneity, as a trait, appeared early on during evolution of the endothelium or whether it appeared later during vertebrate evolution. One way to address this question is to study hagfish, the oldest extant vertebrate. Any feature that is shared by hagfish and humans may be inferred to have evolved in the ancestral vertebrate. Unlike other vertebrates, hagfish are completely devoid of bone and cartilage. However, similar to the jawed vertebrates, hagfish have a closed circulation lined by endothelium. Importantly, our studies revealed that hagfish endothelium is remarkably heterogeneous at the level of ultrastructure, lectin binding, and function (Feng et al. 2007; Yano et al. 2007). We may conclude from these observations that phenotypic heterogeneity evolved as an early feature of the endothelium. In other words, endothelial heterogeneity is not simply a descriptor of many distinct properties of the endothelium, but rather is in itself a core property of the endothelium.

Evolutionary approaches also seek to explain the fitness advantage that a trait confers at a population level. This is a difficult question to definitively answer, but there are two important considerations. One is that the endothelium in traversing the body must provide a broad menu of functions that are adapted to the diverse needs of the underlying tissues. Site-specific differences in function will, in turn, be reflected by structural and molecular heterogeneity. Second, endothelial cells must adapt to different environments simply to survive. For example, endothelial cells in the vasa recta of the inner medulla of the kidney are exposed to profoundly low levels of oxygen, in addition to a hyperosmolar hyperkalemic environment. Although the precise properties of these cells are unknown, it is certain that they are uniquely adapted to this "harsh" environment in ways that render them phenotypically distinct from other types of endothelial cells.

\section{HETEROGENEITY OF TUMOR ENDOTHELIUM}

\section{Scope of Heterogeneity}

As first hypothesized by Folkman, tumors are critically dependent on blood vessels for their nutrient and oxygen delivery (Folkman 1971). Endothelial cells that line tumor blood vessels are normally derived from the surrounding 
tissue, and thus are not part of the malignant clone. In the context of the tumor environment, blood vessels and their endothelial lining acquire abnormal properties. For example, compared with normal blood vessels, tumor vessels are more dilated and tortuous, form arteriovenous shunts, and lack the normal artery-capillary-vein hierarchy (reviewed in Nagy et al. 2010). They have excessive branching, uneven diameters, chaotic flow patterns, and increased permeability to macromolecules. Endothelial cells lining the tumor vessels are structurally abnormal. They often show increased fenestrations and widened intercellular junctions or gaps. They may grow on top of one another and send projections into the vessel lumen. There is redistribution of the phospholipids, phosphatidylethanolamine and phosphatidylserine from the inner to the outer membrane leaflet of tumor endothelial cells (Stafford and Thorpe 2011). Compared with most normal endothelial cells, tumor endothelial cells have a high proliferative rate (Denekamp and Hobson 1982). The basement membrane is discontinuous or absent. Tumor endothelium is variably covered by morphologically abnormal pericytes (Morikawa et al. 2002).

Candidate gene approaches, together with high throughput expression profiling have revealed altered gene and protein expression profiles in tumor endothelium. These properties differ between different tumor types, between blood vessels of a single tumor, and between different stages of tumor progression (reviewed in Aird 2009). For example, the percentage of tumor endothelial cells expressing Tie-2 and vascular growth factor receptor (VEGFR)-2 varies in different human tumors and mouse xenografts (Fathers et al. 2005; Patten et al. 2010). Although most genes that are expressed in tumor endothelial cells are also up-regulated in physiological angiogenic processes, there are important exceptions (Seaman et al. 2007).

\section{Mechanisms of Heterogeneity}

The endothelial lining of tumor blood vessels usually arises from the proliferation of normal endothelial cells from the neighboring tissue.
Thus, the primary determinant of phenotypic heterogeneity in the context of the tumor is the surrounding microenvironment (Fig. 2). Indeed, endothelial cells in the newly formed blood vessels are exposed to a unique blend of extracellular signals that include relative hypoxia, variable blood flow, low $\mathrm{pH}$, hypoglycemia, and soluble mediators released by tumor cells and stromal cells including growth factors (e.g., vascular endothelial growth factor, fibroblast growth factor-2, hepatocyte growth factor, and angiopoietin) and cytokines (e.g., CXCL8 and CXCL1). The nature of these paracrine signals is influenced by multiple factors, including underlying activation of oncogenes and/or the inactivation of tumor suppressor genes in the tumor cells. Recent studies have shown that tumor endothelial cells, in turn, release factors that influence the growth of the tumor (Burridge and Friedman 2010; Franses et al. 2011). Tumor endothelium lacks an organized basement membrane and shows tenuous contact with pericytes. Thus, these endothelial cells are deprived of normal signal inputs.

In addition to the microenvironment, epigenetic factors also play a role in mediating tumor endothelial phenotypes. Whenever tumor blood vessels arise from different vascular beds, their original site-specific epigenetic footprint will be retained even when the cells are exposed to the unique microenvironment of the tumor. Indeed, previous studies in animal models have shown that identical tumor types implanted in different parts of the body display different tumor endothelial phenotypes (e.g., see Fukumura et al. 1997 and Roberts et al. 1998). In addition to the tissue of origin, the epigenetic profile of tumor endothelial cells may be influenced by the tumor environment. For example, previous studies have shown that conditioned medium from tumor cells results in epigenetic alteration of gene expression in cultured endothelial cells (Hellebrekers et al. 2006a,b, 2007). Other studies have shown differences in gene expression profiles in isolated tumor endothelial cells compared with endothelial cells harvested from tissue-matched tissue (Unger et al. 2002; Bussolati et al. 2003). 
W.C. Aird

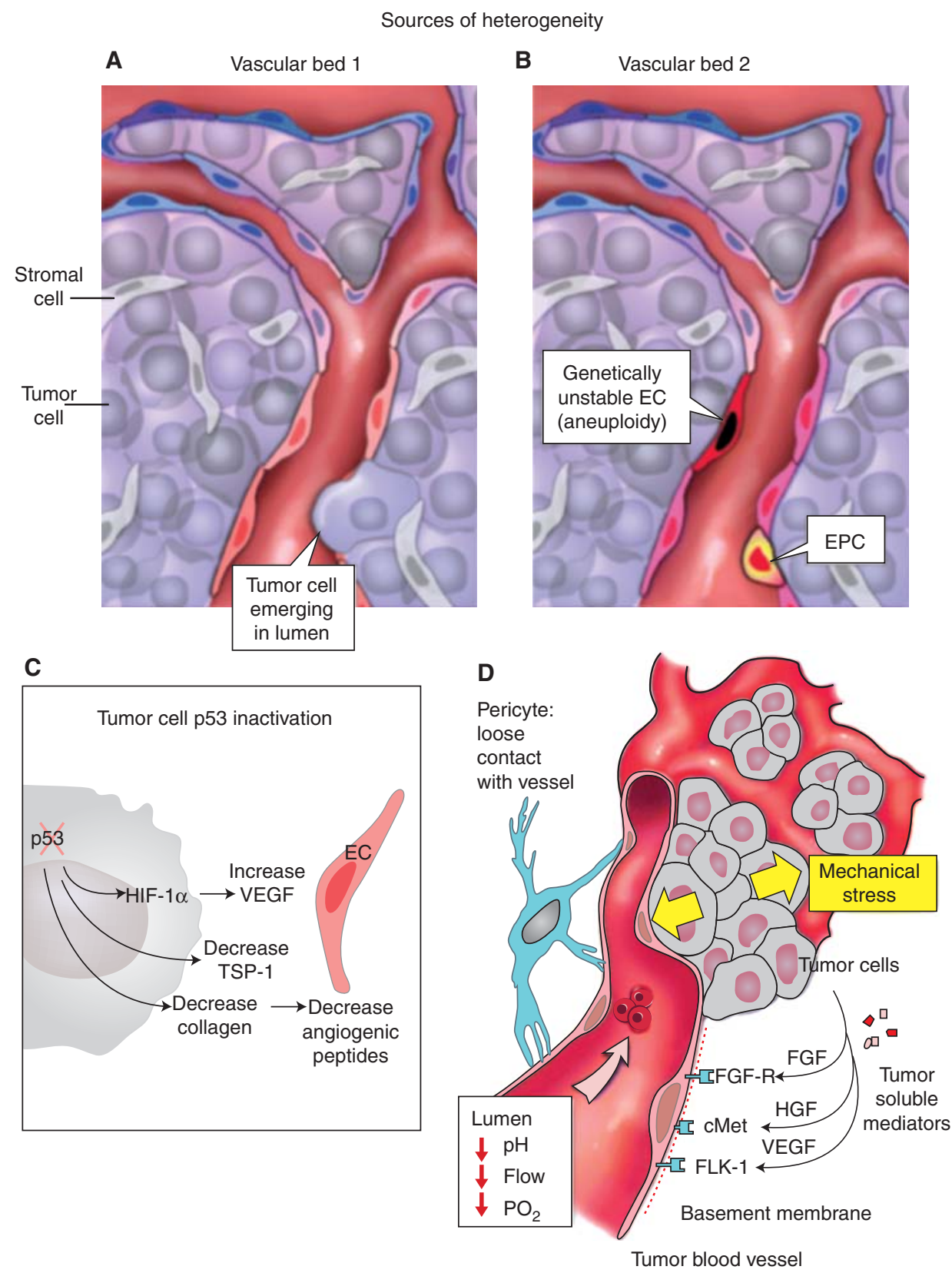

Figure 2. Sources of tumor endothelial cell heterogeneity. $(A, B)$ Tumor endothelial cell phenotypes are determined by the vascular bed of origin (Vascular bed 1 vs. Vascular bed 2), the tumor microenvironment, recruitment and incorporation of bone marrow-derived cells (endothelial progenitor cell, EPC), luminal exposure of tumor cells $(A)$, and genetic instability $(B)$. The different colors represent different tumor endothelial cell phenotypes. The overall differences in color between tumor endothelial cells arising from vascular beds 1 and 2 ( $A, B$, respectively) reflect epigenetically fixed properties. The differences in color between tumor endothelial cells within a given tumor reflect microheterogeneity in the tumor environment. $(C)$ p53 inactivation in tumor cells results in increased hypoxia inducible factor- $1 \alpha$ (HIF-1 $\alpha$ )-dependent expression of vascular endothelial growth factor (VEGF) and reduced expression of thrombospondin-1 (TSP-1) and collagen (and its antiangiogenic peptides). (See facing page for legend.) 
Several other mechanisms may contribute to phenotypic heterogeneity of tumor endothelium. Although controversial, there is some evidence that tumor blood vessels may be lined by bone-marrow-derived cells (see Purhonen et al. 2008, and references therein). Endothelial cells in tumor blood vessels may be genetically unstable. For example, endothelial cells isolated from tumor xenografts showed aneuploidy and multiple centrosomes (Hida et al. 2004). These tumor endothelial cells expressed lower levels of Tie- 1 and Tie- 2 , grew at a faster rate ( $>25$ passages), had reduced serum requirement, and were more responsive to fibroblast growth factor and epidermal growth factor, compared with normal endothelial cells (Hida et al. 2004). Such differences raise the possibility that genetic (as distinct from epigenetic) alterations of tumor endothelial cells may also influence cellular phenotype. Tumors may co-opt existing blood vessels and alter the phenotype of the endothelium (Holash et al. 1999). In some tumors, vessels may be lined, in part, by tumor cells instead of endothelial cells. For example, a recent study reported that a significant fraction of endothelial cells in glioblastoma have a neoplastic origin and that these cells are derived from a population of glioblastoma stemlike cells (Ricci-Vitiani et al. 2010). It is not clear whether the tumor cells mimic endothelial cell function (vasculogenic mimicry) or whether they simply invade the vascular wall and/or become exposed to blood following endothelial cell apoptosis. In any case, the mere presence of luminal tumor cells may interfere with therapies targeted against endothelial determinants.

Certain tumors directly involve endothelial cells, and these cells in turn are likely to possess unique cell autonomous properties. For example, hemangiomas are benign vascular lesions that involve the uncontrolled clonal expansion of endothelial cells (Boye et al. 2001). Molecular profiling has provided evidence for a placental origin of endothelial cells in infantile hemangioma (Barnes et al. 2005). Kaposi's sarcoma, an AIDS-defining vascular tumor, involves a phenotypically unique spindle cell that appears to derive from lymphatic endothelial cells (Wang et al. 2004). A recent report showed a cell autonomous role for Notch 1 in suppressing tumors of the endothelium (Liu et al. 2011). Interestingly, the resulting vascular tumors were more prevalent in liver, compared with other organs.

Evolutionary considerations in cancer (and by extension tumor blood vessels and endothelium) raise two interesting questions. The first question is why are Homo sapiens so vulnerable to developing cancer? Although all multicellular organisms have a propensity to develop both benign and malignant cancer, humans have a substantially greater risk for cancer than other animals, including great apes. The application of evolutionary principles to an understanding of human disease is the domain of a nascent field termed evolutionary medicine (Nesse et al. 2009). Evolutionary biology teaches us that natural selection acts to optimize reproductive success, and not longevity. We now have an extended postreproductive life span. Cancers increase with age and thus are not selected against. Second, no trait is perfect. Every trait may be made better. But by making it better, another trait will be made worse. Viewed from this perspective, the human body is a jerry-rigged bundle of trade-offs that render us vulnerable to disease. An understanding of the risk benefits of these trade-offs may provide insights into the therapy. In cancer, the malignant cells hijack cellular attributes required for normal embryogenesis, self-renewal, and physiological angiogenesis (e.g., wound healing). The angiogenic switch represents an evolutionary trade-off in which the advantages

Figure 2. (Continued) (D) The tumor microenvironment includes signals on the luminal side, e.g., blood hypoxia, reduced blood flow, and low $\mathrm{pH}$, and on the abluminal side, e.g., mechanical pressure from proliferating tumor cells, tumor-derived paracrine mediators, stromal cell-derived signals, and a disorganized basement membrane. FGF, fibroblast growth factor; VEGF, vascular endothelial growth factor; HGF, hepatocyte growth factor; and EC, endothelial cell. (Figure is from Aird 2009; reprinted, with permission, from the author.) 
W.C. Aird

of mediating physiological angiogenesis outweigh the disadvantages of tumor co-option. Finally, owing to our rapid cultural and social evolution, our ancestral genes are not adapted to present-day risk factors, including high-fat diet, contraceptives, tobacco, and alcohol. Thus, the various trade-offs are more likely to manifest as a net liability in the modern environment. Evolutionary considerations yield important therapeutic principles. First, from a preventative standpoint, the reduction of environmental risk factors should help to narrow the gene-environment mismatch. Second, cancer therapy will have a tendency to disrupt the very processes that are being hijacked. Thus, chemotherapy has the unwanted side effect of killing normal stem cells in the bone marrow and interfering with fetal growth. Treatment aimed toward tumor endothelium and blood vessels has the risk of interfering with normal angiogenic processes, including wound healing and pregnancy.

A second evolutionary question is to what extent are there parallels between the evolution of cancer and that of organisms within an ecosystem (reviewed in Merlo et al. 2006 and Goymer 2008)? At the level of the organism, cancer is fatal. However, at the level of individual cells, there is selection for cells with increased proliferative potential. In a process that has been termed somatic evolution, cells in premalignant and malignant tumors evolve by natural selection through the sequential accumulation of somatic mutations that confer a proliferative advantage. With respect to evolutionary theory, cancer meets several important conditions (reviewed in Merlo et al. 2006). First, tumor cells contain variation as evidenced by the existence of many different genetic mutants within the same tumor. Second, these genetic or epigenetic variants are heritable. Finally, selection of clones with high proliferative potential or resistance against apoptosis confers a survival advantage. In addition, clones will be selected for those that evade attack by the immune system and that cooperate with normal cells in the body to promote metastases and to maintain oxygen delivery. Delivery of oxygen requires blood flow, which in turn necessitates hijacking of the angiogenic switch and normal endothelial cells from the surrounding tissue.

\section{Therapy}

There are several advantages to targeting tumor endothelial cells as distinct from the tumor cells. First, the endothelial cells are more accessible to systemically delivered agents. Second, because tumor endothelial cells are not part of the cancer clone, they are less likely to develop resistance to therapies. Third, it has been suggested that inhibition of a single endothelial cell can inhibit up to 100 tumor cells. Thus, treatment aimed toward the endothelium may have an amplifying inhibitory effect.

There are two general approaches for targeting tumor vasculature. The first is to prevent new blood vessel formation by blocking tumorderived angiogenic signals or their receptors on the surface of tumor endothelium. The second strategy is to target preexisting or established tumor blood vessels. The latter approach, termed vascular targeting, may involve vascular disrupting approaches, normalization of the tumor vasculature, or the targeted delivery of agents with the goal of reaching (and in some cases, traversing) the endothelium.

The goal of vascular disrupting therapy is to selectively induce vascular collapse of tumor blood vessels by targeting the cytoskeleton of tumor endothelial cells (reviewed in Hinnen and Eskens 2007). The aim of tumor vessel normalization strategies is to promote the delivery of chemotherapeutic agents to the tumor, to sensitize the tumor to radiation, to enhance tumor immunity, and to render cancer cells less invasive and metastatic (reviewed in Sato 2011). However, vascular remodeling (e.g., induced by anti-VEGF treatment) may lead to a more hypoxic tumor microenvironment and increased tumor cell invasion (Keunen et al. 2011). Targeted delivery of drugs to tumor endothelium takes advantage of vascular markers that are preferentially expressed on tumor endothelium. The target molecule may or may not be involved in tumor pathophysiology. Indeed, more often than not, the target serves simply to localize the effector molecule, 
allowing for site-specific toxicity at the level of the tumor. Several types of carrier molecules or ligands have been developed, including monoclonal antibodies, aptamers, peptides, and small organic molecules. Among the targets that have shown promise in animal/preclinical studies are Tie-2, fibronectin extra-domain B, $\alpha v \beta 3$ and $\alpha 5 \beta 1$ integrins, annexin $\mathrm{Ala}$, and prostate-specific membrane antigen (PMSA) (see Aird 2009, and references therein).

An important challenge is to translate the findings of large-scale gene expression and protein profiling into diagnostic and/or therapeutic advances. This will involve the improved use of in silico approaches to filter the enormous databases, the identification of peptide-binding receptors (in the case of phage display), the validation of tissue-type specificity, an understanding of the pathophysiological role that such markers play in angiogenesis, tumor growth/progression, or metastases, and the extent to which results in mice will translate to humans. These caveats notwithstanding, the continued discovery and validation of novel tumor endothelial-specific markers should provide a foundation for advances in therapy. Moreover, the identification of tumor vascular-bed-specific "addresses" should facilitate the development of molecular imaging for diagnosis and surveillance.

\section{CONCLUDING REMARKS}

This article began with the observation that there exists an enormous bench-to-bedside gap in endothelial biomedicine. One of the reasons for this chasm is the tendency to approach the vasculature through the limited lens of large arteries and veins, when in fact the endothelium is a spatially distributed organ system. Like a chameleon, it molds itself to the needs of the underlying tissue. The ability to meet the diverse demands of so many tissues is reflected in a seemingly endless repertoire of structural and functional phenotypes, some of which are dependent on signals in the microenvironment, and others that are epigenetically fixed. Based on studies of early vertebrates, it seems likely that the endothelium has marched to the tune of the local tissue environment since its evolutionary inception some 500 million years ago. Importantly, phenotypic heterogeneity may be leveraged for therapeutic gain, in particular, for targeting specific sites of the vasculature. These principles have been applied to an understanding of tumor endothelium. A similar conceptual approach may be applied to any number of vascular beds in health and disease.

\section{REFERENCES}

Aird WC. 2001. Vascular bed-specific hemostasis: Role of endothelium in sepsis pathogenesis. Crit Care Med 29: S28-S35.

Aird WC. 2006. Mechanisms of endothelial cell heterogeneity in health and disease. Circ Res 98: 159-162.

Aird WC. 2007a. Phenotypic heterogeneity of the endothelium: I. Structure, function, and mechanisms. Circ Res 100: $158-173$.

Aird WC. 2007b. Phenotypic heterogeneity of the endothelium: II. Representative vascular beds. Circ Res 100: 174- 190 .

Aird WC. 2009. Molecular heterogeneity of tumor endothelium. Cell Tissue Res 335: 271-281.

Aitsebaomo J, Portbury AL, Schisler JC, Patterson C. 2008. Brothers and sisters: Molecular insights into arterialvenous heterogeneity. Circ Res 103: 929-939.

Arap W, Pasqualini R, Ruoslahti E. 1998. Cancer treatment by targeted drug delivery to tumor vasculature in a mouse model. Science 279: 377-380.

Arap W, Haedicke W, Bernasconi M, Kain R, Rajotte D, Krajewski S, Ellerby HM, Bredesen DE, Pasqualini R, Ruoslahti E. 2002a. Targeting the prostate for destruction through a vascular address. Proc Natl Acad Sci 99: 1527-1531.

Arap W, Kolonin MG, Trepel M, Lahdenranta J, Cardo-Vila M, Giordano RJ, Mintz PJ, Ardelt PU, Yao VJ, Vidal CI et al. 2002b. Steps toward mapping the human vasculature by phage display. Nat Med 8: 121-127.

Aurrand-Lions M, Johnson-Leger C, Imhof BA. 2002. The last molecular fortress in leukocyte trans-endothelial migration. Nat Immunol 3: 116-118.

Barnes CM, Huang S, Kaipainen A, Sanoudou D, Chen EJ, Eichler GS, Guo Y, Yu Y, Ingber DE, Mulliken JB, et al. 2005. Evidence by molecular profiling for a placental origin of infantile hemangioma. Proc Natl Acad Sci 102: 19097-19102.

Basit A, Reutershan J, Morris MA, Solga M, Rose CE Jr, Ley K. 2006. ICAM-1 and LFA-1 play critical roles in LPSinduced neutrophil recruitment into the alveolar space. Am J Physiol Lung Cell Mol Physiol 291: L200-L207.

Bendayan M. 2002. Morphological and cytochemical aspects of capillary permeability. Microsc Res Tech 57: 327-349.

Boye E, Yu Y, Paranya G, Mulliken JB, Olsen BR, Bischoff J. 2001. Clonality and altered behavior of endothelial cells from hemangiomas. J Clin Invest 107: 745-752. 
W.C. Aird

Burridge KA, Friedman MH. 2010. Environment and vascular bed origin influence differences in endothelial transcriptional profiles of coronary and iliac arteries. Am J Physiol Heart Circ Physiol 299: H837-H846.

Bussolati B, Deambrosis I, Russo S, Deregibus MC, Camussi G. 2003. Altered angiogenesis and survival in human tumor-derived endothelial cells. FASEB J 17: 1159-1161.

Butcher EC. 1991. Leukocyte-endothelial cell recognition: Three (or more) steps to specificity and diversity. Cell 67: 1033-1036.

Chi JT, Chang HY, Haraldsen G, Jahnsen FL, Troyanskaya OG, Chang DS, Wang Z, Rockson SG, van de Rijn M, Botstein D, et al. 2003. Endothelial cell diversity revealed by global expression profiling. Proc Natl Acad Sci 100: 10623-10628

Denekamp J, Hobson B. 1982. Endothelial-cell proliferation in experimental tumours. Br J Cancer 46: 711-720.

Dvorak AM, Feng D. 2001. The vesiculo-vacuolar organelle (VVO). A new endothelial cell permeability organelle. J Histochem Cytochem 49: 419-432.

Fathers KE, Stone CM, Minhas K, Marriott JJ, Greenwood JD, Dumont DJ, Coomber BL. 2005. Heterogeneity of Tie2 expression in tumor microcirculation: Influence of cancer type, implantation site, and response to therapy. Am J Pathol 167: 1753-1762.

Feng J, Yano K, Monahan-Earley R, Morgan ES, Dvorak AM, Sellke FW, Aird WC. 2007. Vascular bed-specific endothelium-dependent vasomomotor relaxation in the hagfish, Myxine glutinosa. Am J Physiol Regul Integr Comp Physiol 293: R894-R900.

Flaherty JT, Pierce JE, Ferrans VJ, Patel DJ, Tucker WK, Fry DL. 1972. Endothelial nuclear patterns in the canine arterial tree with particular reference to hemodynamic events. Circ Res 30: 23-33.

Folkman J. 1971. Tumor angiogenesis: Therapeutic implications. N Engl J Med 285: 1182-1186.

Franco CA, Liebner S, Gerhardt H. 2009. Vascular morphogenesis: AWnt for every vessel? Curr Opin Genet Dev 19: 476-483.

Franses JW, Baker AB, Chitalia VC, Edelman ER. 2011. Stromal endothelial cells directly influence cancer progression. Sci Transl Med 3: 66ra5.

Fukumura D, Yuan F, Monsky WL, Chen Y, Jain RK. 1997. Effect of host microenvironment on the microcirculation of human colon adenocarcinoma. Am J Pathol 151: 679-688.

Goymer P. 2008. Natural selection: The evolution of cancer. Nature 454: 1046-1048.

Hellebrekers DM, Castermans K, Vire E, Dings RP, Hoebers NT, Mayo KH, Oude Egbrink MG, Molema G, Fuks F, van Engeland M, et al. 2006a. Epigenetic regulation of tumor endothelial cell anergy: Silencing of intercellular adhesion molecule-1 by histone modifications. Cancer Res 66: $10770-10777$.

Hellebrekers DM, Jair KW, Vire E, Eguchi S, Hoebers NT, Fraga MF, Esteller M, Fuks F, Baylin SB, van Engeland M, et al. 2006b. Angiostatic activity of DNA methyltransferase inhibitors. Mol Cancer Ther 5: 467-475.

Hellebrekers DM, Melotte V, Vire E, Langenkamp E, Molema G, Fuks F, Herman JG, Van Criekinge W, Griffioen AW, van Engeland M. 2007. Identification of epigenetically silenced genes in tumor endothelial cells. Cancer Res 67: 4138-4148.

Hida K, Hida Y, Amin DN, Flint AF, Panigrahy D, Morton CC, Klagsbrun M. 2004. Tumor-associated endothelial cells with cytogenetic abnormalities. Cancer Res 64: 8249-8255.

Hinnen P, Eskens FA. 2007. Vascular disrupting agents in clinical development. Br J Cancer 96: 1159-1165.

Holash J, Maisonpierre PC, Compton D, Boland P, Alexander CR, Zagzag D, Yancopoulos GD, Wiegand SJ. 1999. Vessel cooption, regression, and growth in tumors mediated by angiopoietins and VEGF. Science 284: 1994-1998.

Hwa C, Sebastian A, Aird WC. 2005. Endothelial biomedicine: Its status as an interdisciplinary field, its progress as a basic science, and its translational bench-to-bedside gap. Endothelium 12: 139-151.

Keunen O, Johansson M, Oudin A, Sanzey M, Rahim SA, Fack F, Thorsen F, Taxt T, Bartos M, Jirik R, et al. 2011. Anti-VEGF treatment reduces blood supply and increases tumor cell invasion in glioblastoma. Proc Natl Acad Sci 108: $3749-3754$

Lacorre DA, Baekkevold ES, Garrido I, Brandtzaeg P, Haraldsen G, Amalric F, Girard JP. 2004. Plasticity of endothelial cells: Rapid dedifferentiation of freshly isolated high endothelial venule endothelial cells outside the lymphoid tissue microenvironment. Blood 103: $4164-4172$.

Laszik Z, Mitro A, Taylor FB Jr, Ferrell G, Esmon CT. 1997. Human protein $C$ receptor is present primarily on endothelium of large blood vessels: Implications for the control of the protein C pathway. Circulation 96: 3633 3640 .

Levin EG, Banka CL, Parry GC. 2000. Progressive and transient expression of tissue plasminogen activator during fetal development. Arterioscler Thromb Vasc Biol 20: $1668-1674$.

Liu Z, Turkoz A, Jackson EN, Corbo JC, Engelbach JA, Garbow JR, Piwnica-Worms DR, Kopan R. 2011. Notch1 loss of heterozygosity causes vascular tumors and lethal hemorrhage in mice. J Clin Invest 121: 800-808.

McIntosh DP, Tan XY, Oh P, Schnitzer JE. 2002. Targeting endothelium and its dynamic caveolae for tissue-specific transcytosis in vivo: A pathway to overcome cell barriers to drug and gene delivery. Proc Natl Acad Sci 99: 1996-2001.

Merlo LM, Pepper JW, Reid BJ, Maley CC. 2006. Cancer as an evolutionary and ecological process. Nat Rev Cancer 6: 924-935.

Minami T, Aird WC. 2005. Endothelial cell gene regulation. Trends Cardiovasc Med 15: 174-184.

Miyasaka M, Tanaka T. 2004. Lymphocyte trafficking across high endothelial venules: Dogmas and enigmas. Nat Rev Immunol 4: 360-370.

Morikawa S, Baluk P, Kaidoh T, Haskell A, Jain RK, McDonald DM. 2002. Abnormalities in pericytes on blood vessels and endothelial sprouts in tumors. Am J Pathol 160: 985-1000.

Nagy JA, Chang SH, Shih SC, Dvorak AM, Dvorak HF. 2010. Heterogeneity of the tumor vasculature. Semin Thromb Hemost 36: 321-331. 
Nesse RM, Bergstrom CT, Ellison PT, Flier JS, Gluckman P, Govindaraju DR, Niethammer D, Omenn GS, Perlman RL, Schwartz MD, et al. 2009. Evolution in health and medicine Sackler Colloquium: Making evolutionary biology a basic science for medicine. Proc Natl Acad Sci 107: $1800-1807$

Nishio K, Suzuki Y, Aoki T, Suzuki K, Miyata A, Sato N, Naoki K, Kudo H, Tsumura H, Serizawa H, et al. 1998. Differential contribution of various adhesion molecules to leukocyte kinetics in pulmonary microvessels of hyperoxia-exposed rat lungs. Am J Respir Crit Care Med 157: 599-609.

Nitta T, Hata M, Gotoh S, Seo Y, Sasaki H, Hashimoto N, Furuse M, Tsukita S. 2003. Size-selective loosening of the blood-brain barrier in claudin-5-deficient mice. J Cell Biol 161: 653-660.

Osterud B, Bajaj MS, Bajaj SP. 1995. Sites of tissue factor pathway inhibitor (TFPI) and tissue factor expression under physiologic and pathologic conditions. On behalf of the Subcommittee on Tissue factor Pathway Inhibitor (TFPI) of the Scientific and Standardization Committee of the ISTH. Thromb Haemost 73: 873-875.

Pasqualini R, Ruoslahti E. 1996. Organ targeting in vivo using phage display peptide libraries. Nature 380: $364-$ 366.

Passerini AG, Polacek DC, Shi C, Francesco NM, Manduchi E, Grant GR, Pritchard WF, Powell S, Chang GY, Stoeckert CJJr, et al. 2004. Coexisting proinflammatory and antioxidative endothelial transcription profiles in a disturbed flow region of the adult porcine aorta. Proc Natl Acad Sci 101: 2482-2487.

Patten SG, Adamcic U, Lacombe K, Minhas K, Skowronski K, Coomber BL. 2010. VEGFR2 heterogeneity and response to anti-angiogenic low dose metronomic cyclophosphamide treatment. BMC Cancer 10: 683.

Petzelbauer P, Bender JR, Wilson J, Pober JS. 1993. Heterogeneity of dermal microvascular endothelial cell antigen expression and cytokine responsiveness in situ and in cell culture. J Immunol 151: 5062-5072.

Purhonen S, Palm J, Rossi D, Kaskenpaa N, Rajantie I, Yla-Herttuala S, Alitalo K, Weissman IL, Salven P. 2008. Bone marrow-derived circulating endothelial precursors do not contribute to vascular endothelium and are not needed for tumor growth. Proc Natl Acad Sci 105: $6620-6625$.

Ricci-Vitiani L, Pallini R, Biffoni M, Todaro M, Invernici G, Cenci T, Maira G, Parati EA, Stassi G, Larocca LM, et al. 2010. Tumour vascularization via endothelial differentiation of glioblastoma stem-like cells. Nature 468: 824-828.

Roberts WG, Delaat J, Nagane M, Huang S, Cavenee WK, Palade GE. 1998. Host microvasculature influence on tumor vascular morphology and endothelial gene expression. Am J Pathol 153: 1239-1248.
Rosenberg RD, Aird WC. 1999. Vascular-bed-specific hemostasis and hypercoagulable states. $N$ Engl J Med 340: $1555-1564$.

Ruoslahti E, Rajotte D. 2000. An address system in the vasculature of normal tissues and tumors. Annu Rev Immunol 18: 813-827.

Sato Y. 2011. Persistent vascular normalization as an alternative goal of anti-angiogenic cancer therapy. Cancer Sci 102: $1253-1256$

Seaman S, Stevens J, Yang MY, Logsdon D, Graff-Cherry C, St Croix B. 2007. Genes that distinguish physiological and pathological angiogenesis. Cancer Cell 11: 539-554.

Simionescu M, Gafencu A, Antohe F. 2002. Transcytosis of plasma macromolecules in endothelial cells: A cell biological survey. Microsc Res Tech 57: 269-288.

Simonson AB, Schnitzer JE. 2007. Vascular proteomic mapping in vivo. J Thromb Haemost 5 (Suppl 1): 183-187.

Springer TA. 1994. Traffic signals for lymphocyte recirculation and leukocyte emigration: The multistep paradigm. Cell 76: 301-314.

Stafford JH, Thorpe PE. 2011. Increased exposure of phosphatidylethanolamine on the surface of tumor vascular endothelium. Neoplasia 13: 299-308.

Tinbergen N. 1963. On aims and methods in ethology. $Z$ Tierpsychol 20: 410-433.

Unger RE, Oltrogge JB, von Briesen H, Engelhardt B, Woelki U, Schlote W, Lorenz R, Bratzke H, Kirkpatrick CJ. 2002. Isolation and molecular characterization of brain microvascular endothelial cells from human brain tumors. In Vitro Cell Dev Biol Anim 38: 273-281.

Wang HW, Trotter MW, Lagos D, Bourboulia D, Henderson S, Makinen T, Elliman S, Flanagan AM, Alitalo K, Boshoff C. 2004. Kaposi sarcoma herpesvirus-induced cellular reprogramming contributes to the lymphatic endothelial gene expression in Kaposi sarcoma. Nat Genet 36: 687-693.

Wisse E. 1970. An electron microscopic study of the fenestrated endothelial lining of rat liver sinusoids. J Ultrastruct Res 31: 125-150.

Wong J, Johnston B, Lee SS, Bullard DC, Smith CW, Beaudet AL, Kubes P. 1997. A minimal role for selectins in the recruitment of leukocytes into the inflamed liver microvasculature. J Clin Invest 99: 2782-2790.

Yano K, Gale D, Massberg S, Cheruvu PK, Monahan-Earley R, Morgan ES, Haig D, von Andrian UH, Dvorak AM, Aird WC. 2007. Phenotypic heterogeneity is an evolutionarily conserved feature of the endothelium. Blood 109: 613-615.

Zhang J, Burridge KA, Friedman MH. 2008. In vivo differences between endothelial transcriptional profiles of coronary and iliac arteries revealed by microarray analysis. Am J Physiol Heart Circ Physiol 295: H1556-H1561. 


\section{$\&_{\mathrm{CSH}}^{\infty} \&$ Cold Spring Harbor

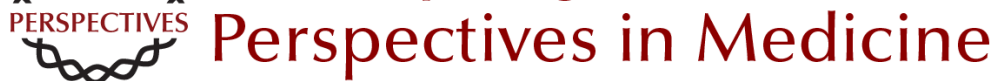

\section{Endothelial Cell Heterogeneity}

William C. Aird

Cold Spring Harb Perspect Med 2012; doi: 10.1101/cshperspect.a006429 originally published online October 6, 2011

\section{Subject Collection Angiogenesis}

Extracellular Matrix Regulation of Vascular Morphogenesis, Maturation, and Stabilization George E. Davis and Scott S. Kemp

Endothelial Cell-Pericyte Interactions in the Pathogenesis of Cerebral Cavernous Malformations (CCMs) Wang Min and Jenny Huanjiao Zhou

Lymphatic Clearance and Pump Function Jerome W. Breslin

Platelets and (Lymph)angiogenesis Harvey G. Roweth and Elisabeth M. Battinelli

Modeling Brain Vasculature Immune Interactions In Vitro Ruth Lyck, Hideaki Nishihara, Sidar Aydin, et al.

Human Endothelial Colony-Forming Cells Juan M. Melero-Martin

\section{The Beauty and Complexity of Blood Vessel} Patterning

Victoria L. Bautch and Yoh-suke Mukouyama

Endothelialitis, Microischemia, and

Intussusceptive Angiogenesis in COVID-19 Steven J. Mentzer, Maximilian Ackermann and Danny Jonigk
Regulation of the Blood-Brain Barrier in Health and Disease

Cara C. Rada, Kanako Yuki, Jie Ding, et al.

Targeting Angiogenesis via Resolution of

Inflammation

Abigail G. Kelly and Dipak Panigrahy

Notch Signaling in the Vasculature: Angiogenesis and Angiocrine Functions

Sana S. Hasan and Andreas Fischer

Signal Transduction and Gene Regulation in the Endothelium

Michel V. Levesque and Timothy Hla

Buttons and Zippers: Endothelial Junctions in

Lymphatic Vessels

Peter Baluk and Donald M. McDonald

Endothelial Cell Fate Determination: A Top Notch Job in Vascular Decision-Making

L.A. Naiche, Stephanie R. Villa and Jan K. Kitajewski

Leukocyte Trafficking in Lymphatic Vessels Aline Bauer, Hazal Tatliadim and Cornelia Halin

Lymphatic Tissue and Organ Engineering for In Vitro Modeling and In Vivo Regeneration Anna M. Kolarzyk, Gigi Wong and Esak Lee

For additional articles in this collection, see http://perspectivesinmedicine.cshlp.org/cgi/collection/ 